Article

\title{
Approximation of Endpoints for $\alpha$-Reich-Suzuki Nonexpansive Mappings in Hyperbolic Metric Spaces
}

\author{
Izhar Uddin ${ }^{1, *(\mathbb{D}, \text { Sajan Aggarwal }}{ }^{1}$ and Afrah A. N. Abdou ${ }^{2}$ \\ 1 Department of Mathematics, Jamia Millia Islamia, New Delhi 110025, India; \\ aggarwal.maths1993@gmail.com \\ 2 Mathematics Department, Faculty of Science, University of Jeddah, P.O. Box 80327, \\ Jeddah 21589, Saudi Arabia; aabdou@uj.edu.sa \\ * Correspondence: izharuddin1@jmi.ac.in
}

check for

updates

Citation: Uddin, I.; Aggarwal, S.; Abdou, A.A.N. Approximation of Endpoints for $\alpha$-Reich-Suzuki Nonexpansive Mappings in Hyperbolic Metric Spaces. Mathematics 2021, 9, 1692. https:// doi.org/10.3390/math9141692

Academic Editors: Jong Kyu Kim, Yeol Je Cho, Sang-Eon Han,

Christopher Goodrich and Ravi P. Agarwal

Received: 31 May 2021

Accepted: 14 July 2021

Published: 19 July 2021

Publisher's Note: MDPI stays neutral with regard to jurisdictional claims in published maps and institutional affiliations.

Copyright: (c) 2021 by the authors. Licensee MDPI, Basel, Switzerland. This article is an open access article distributed under the terms and conditions of the Creative Commons Attribution (CC BY) license (https:// creativecommons.org/licenses/by/ $4.0 /)$.

\begin{abstract}
The concept of an endpoint is a relatively new concept compared to the concept of a fixed point. The aim of this paper is to perform a convergence analysis of $M$-iteration involving $\alpha$ - ReichSuzuki nonexpansive mappings. In this paper, we prove strong and $\Delta$-convergence theorems in a hyperbolic metric space. Thus, our results generalize and improve many existing results.
\end{abstract}

Keywords: hyperbolic metric space; $\alpha$-Riech-Suzuki nonexpansive mapping; fixed point theorems; endpoint

JEL Classification: $47 \mathrm{H} 10$

\section{Introduction}

Due to its wide applications, fixed point theory is a very fast-growing research area of nonlinear analysis. There are two main problems that arise in this active research area. The first problem deals with the existence of fixed points with respect to different nonlinear mappings, while the second problem concerns the convergence analysis of a fixed point. To study the convergence analysis of a fixed point for single valued mapping, many iteration processes have been developed, for example, Mann iteration [1], Ishikawa [2], Halpern [3], Agarwal [4], Noor [5] and $M$-iteration [6] and some others. Sastry and Babu [7] utilized the Mann and Ishikawa iteration process to approximate a fixed point of multivalued mappings in a Hilbert space. Panyanak [8] extended the result of Sastry and Babu [7] to the uniformly convex Banach space. One of the interesting research problems in the fixed point theory of Banach spaces is to generalize the class of nonexpansive mappings. It is worth mentioning here that convexity plays a very important part in metric fixed point theory. Therefore, beyond the Banach space, there are interesting challenges to obtaining similar results. Thus, hyperbolic metric spaces provide a natural platform to study metric fixed point results.

Endpoint (also called a strict fixed point) of multivalued mapping is a restrictive condition rather than a fixed point. If a multivalued mapping has a fixed point, then the endpoint of that mapping may or may not exist. In 2003, Rus [9] proved some results on endpoints. Several authors have studied the existence of an endpoint for multivalued mapping in a Banach space, e.g., [10-17]. Very recently, Panyanak [18] utilized an Ishikawa type iteration process to approximate endpoint of multivalued nonexpansive mapping. In 2008, Suzuki introduced a class of mappings, which is a larger class of mappings than the class of nonexpanive mappings. Many authors approximate the endpoint of Suzuki nonexpansive mapping by using different iterations; see $[6,19,20]$.

The aim of this paper is twofold and can be described as follows:

We perform a convergence analysis of M-iteration to the endpoint of a generalized nonexpansive mapping (concretely, $\alpha$-Reich-Suzuki nonexpansive mapping). We also extend our domain from a linear to nonlinear domain viz:hyperbolic metric space. 


\section{Preliminaries}

Let $(X, d)$ be a metric space and $K$ be a nonempty subset of $X$. For $x \in X$, set

$$
d(x, K)=\inf \{d(x, y): y \in K\},
$$

here $d(x, K)$ is known as distance from $x$ to $K$. We shall denote the set of all nonempty and compact subsets of $K$ by $C(K)$. Set

$$
H(A, B)=\max \left\{\sup _{a \in A} d(a, B), \sup _{b \in B} d(b, A)\right\},
$$

for each $A, B \in C(K), H(.,$.$) is known as the Hausdorff metric on C(K)$.

A multivalued mapping $T: K \rightarrow C(K)$ is said to be nonexpansive mapping if

$$
H(T x, T y) \leq d(x, y),
$$

for each $x, y \in K$.

A point $p \in K$ is said to be fixed point of $T: K \rightarrow C(K)$ if $p \in T p$ and endpoint or stationary point if $T p=p$. The set of fixed points is denoted by $F_{T}$ and endpoints is denoted by $E_{T} . T: K \rightarrow C(K)$ is said to satisfy the endpoint condition if $E_{T}=F_{T}$.

Recently, in 2019, Pandey et al. [21] introduced a new mapping, namely $\alpha$-ReichSuzuki nonexpansive mapping, which generalizes all previous mappings in the literature. We present here a multivalued version of $\alpha$-Reich-Suzuki nonexpansive mapping.

Definition 1. A mapping $T$ defined on a nonempty subset $K$ of hyperbolic metric space is said to be multivalued $\alpha$-Reich-Suzuki nonexpansive mapping if for all $x, y \in K$ and $\alpha \in[0,1)$,

$$
\frac{1}{2} d(x, T x) \leq d(x, y) \Rightarrow H(T x, T y) \leq \max \{P(x, y), Q(x, y)\}
$$

where

$$
P(x, y)=\alpha d(T x, x)+\alpha d(T y, y)+(1-2 \alpha) d(x, y)
$$

and

$$
Q(x, y)=\alpha d(T x, y)+\alpha d(T y, x)+(1-2 \alpha) d(x, y) .
$$

In 1990, Reich and Shafrir [22] introduced hyperbolic metric space and studied an iteration process for nonexpansive mappings in these spaces. In 2004, Kohlenbach [23] introduced a more general hyperbolic metric space. In this paper, we use the definition of a hyperbolic metric space given by Kohlenbach [23].

Definition 2. Let $(X, d)$ be a metric space, then $(X, d, W)$ will be the hyperbolic metric space if the function $W: X \times X \times[0,1] \rightarrow X$ satisfying

(i) $\quad d(z, W(x, y, \alpha)) \leq(1-\alpha) d(z, x)+\alpha d(z, y)$,

(ii) $\quad d(W(x, y, \alpha), W(x, y, \beta))=|\alpha-\beta| d(x, y)$,

(iii) $W(x, y, \alpha)=W(x, y, 1-\alpha)$,

(iv) $\quad d(W(x, y, \alpha), W(z, w, \alpha)) \leq(1-\alpha) d(x, z)+\alpha d(y, w)$

for all $x, y, z, w \in X$ and $\alpha, \beta \in[0,1]$.

A linear example of a hyperbolic metric space is a Banach space, and nonlinear examples are Hadamard manifolds, the Hilbert open unit ball equipped with the hyperbolic metric (for more information concerning the Hilbert ball, see [24]) and the CAT(0) spaces.

The generalization of the definition of uniformly convex in metric space was first given by Goebel et al. [25]. 
Definition 3. Let $(X, d)$ be a hyperbolic metric space. We say that $X$ is uniformly convex if for any $a \in X$, for every $r>0$, and for each $\varepsilon>0$

$$
\delta(r, \varepsilon)=\inf \left\{1-\frac{1}{r} d\left(W\left(x, y, \frac{1}{2}\right), a\right) ; d(x, a) \leq r, d(y, a) \leq r, d(x, y) \geq r \varepsilon\right\}>0 .
$$

Definition 4. Let $(X, d)$ be a uniformly convex hyperbolic space. For each $r>0$ and $\varepsilon \in(0,2]$, we define

$$
\psi(r, \epsilon)=\inf \left\{\frac{1}{2} d^{2}(a, z)+\frac{1}{2} d^{2}(b, z)-d^{2}\left(W\left(a, b, \frac{1}{2}\right), z\right)\right\},
$$

where the infimum is taken over each $a, b, z \in X$ such that $d(a, z) \leq r, d(b, z) \leq r$ and $d(a, b) \geq r \epsilon$. We say that $(X, d)$ is 2-uniformly convex if

$$
C_{X}=\inf \left\{\frac{\phi(r, \epsilon)}{r^{2} \epsilon^{2}}: r \in(0, \infty), \epsilon(0,2]\right\}>0 .
$$

A uniformly convex Banach space and $C A T(0)$ spaces as well as $C A T(k)$ spaces $\left(k>0\right.$ and diam $\left.(M) \leq\left((\pi / 2-\epsilon) / k^{1 / 2}\right)\right)$ for some $\epsilon \in(0, \pi / 2)$ are 2-uniformly convex hyperbolic spaces.

Definition 5. Let $X$ be a complete hyperbolic metric space and $\left\{x_{n}\right\}$ be a bounded sequence in $X$. Then, the type function $\tau\left(.,\left\{x_{n}\right\}\right): X \rightarrow[0, \infty)$ is defined by

$$
\tau(x)=\limsup _{n \rightarrow \infty} d\left(x, x_{n}\right) .
$$

The asymptotic radius $r\left(\left\{x_{n}\right\}\right)$ is given by

$$
r\left(X,\left\{x_{n}\right\}\right)=\inf \{\tau(x): \text { for } x \in X\}
$$

and the asymptotic center $A\left(\left\{x_{n}\right\}\right)$ of $\left\{x_{n}\right\}$ is defined as

$$
A\left(\left\{x_{n}\right\}\right)=\left\{x \in X: \tau(x)=r\left(\left\{x_{n}\right\}\right)\right\} .
$$

Definition 6. The sequence $\left\{x_{n}\right\}$ is called regular relative to $K$ if $r\left(K,\left\{x_{n}\right\}\right)=r\left(K,\left\{x_{n_{i}}\right\}\right)$ for every subsequence $\left\{x_{n_{i}}\right\}$ of $\left\{x_{n}\right\}$.

Lemma 1 ([26]). Every bounded sequence in hyperbolic metric space has a regular subsequence.

Definition 7. A bounded sequence $\left\{x_{n}\right\}$ in $X$ is said to $\Delta$-converge to $x \in X$ if $x$ is the unique asymptotic center of every subsequence $\left\{u_{n}\right\}$ of $\left\{x_{n}\right\}$. We write $x_{n} \rightarrow x\left(\left\{x_{n}\right\} \Delta\right.$-converges to $\left.x\right)$.

Definition 8. A mapping $T: K \rightarrow C(K)$ is said to satisfy condition ( $J)$ if there is a nondecreasing function $\lambda:[0, \infty) \rightarrow[0, \infty)$ with $\lambda(0)=0, \lambda(t)>0$ for $t \in(0, \infty)$ such that

$$
D(x, T x) \geq \lambda(d(x, E(T)))
$$

for each $x \in K$.

Definition 9. A mapping $T: K \rightarrow C(K)$ is said to be semi-compact if for every sequence $\left\{x_{n}\right\}$ in K such that

$$
\lim _{n \rightarrow \infty} r_{x_{n}}\left(T x_{n}\right)=0,
$$

there is a subsequence $\left\{x_{n_{j}}\right\}$ of $\left\{x_{n}\right\}$ such that $\lim _{j \rightarrow \infty} x_{n_{j}}=z$ for some $z \in K$.

We see that if $K$ is compact, then every multivalued mapping $T: K \rightarrow C(K)$ is semicompact. 
Definition 10. A sequence $\left\{x_{n}\right\}$ in $X$ is called Fejer-monotone with respect to $K$ if $d\left(x_{n+1}, p\right) \leq$ $d\left(x_{n}, p\right)$, for each $p \in K$ and $n \in \mathbb{N}$.

Proposition 1 ([19]). Let $K$ be a nonempty closed subset of complete 2-uniformly convex hyperbolic metric space and $\left\{x_{n}\right\}$ be a Fejér monotone sequence with respect to $K$. Then, $\left\{x_{n}\right\}$ converges strongly to a point of $K$ if and only if $\lim _{n \rightarrow \infty} d\left(x_{n}, K\right)=0$.

Lemma 2 ([21]). Let $T$ be a generalized $\alpha$-Reich-Suzuki nonexpansive mapping on a nonempty subset $C$ of a hyperbolic space; then, for all $x, y \in C$

$$
d(x, T y) \leq\left(\frac{3+\alpha}{1-\alpha}\right) d(x, T x)+d(x, y)
$$

The proof of this lemma is simple, and it can be followed from the line of proof of Theorem 3.1 of [20].

Lemma 3. Let $K$ be a nonempty bounded closed convex subset of $X$ and $T: K \rightarrow C(K)$ be a multivalued $\alpha$-Reich-Suzuki nonexpansive mapping. Then, $T$ has an endpoint if and only if $T$ has the approximate endpoint property.

Lemma 4 ([27]). Let $(X, d)$ be a 2-uniformly convex hyperbolic metric space then,

$$
d^{2}(W(x, y, \alpha), z) \leq(1-\alpha) d^{2}(x, z)+\alpha d^{2}(y, z)-4 C_{X} \alpha(1-\alpha) d^{2}(x, y),
$$

for each $\alpha \in[0,1]$ and $x, y, z \in X$.

Definition 11. Let $K$ be a nonempty subset of a metric space $(X, d)$ and $x \in X$. The radius of $K$ relative to $x$ is defined by

$$
r_{x}:=\sup \{d(x, y): y \in K\} .
$$

The diameter of $K$ is defined by

$$
\operatorname{diam}(K):=\sup \{d(x, y): x, y \in K\} .
$$

The set $K$ is said to be bounded if $\operatorname{diam}(E)<\infty$.

Lemma 5 ([18]). For a multivalued mapping $T: K \rightarrow C(K)$, the following statements hold.

(a) $d(x, T x)=0 \Leftrightarrow x$ is a fixed point of $T$.

(b) $r_{x}(T x)=0 \Leftrightarrow x$ is an endpoint of $T$.

Lemma 6. Let $\alpha_{n}$ be a real sequence such that $\alpha_{n} \in[0,1]$ and $\sum \alpha_{n}\left(1-\alpha_{n}\right)=\infty$. Let $\beta_{n}$ be the sequence of nonnegative sequence of real numbers such that $\sum \alpha_{n}\left(1-\alpha_{n}\right) \beta_{n}$ is bounded. Then, $\beta_{n}$ has a subsequence, which converges to zero.

Proof. The proof is simple and can be proven easily.

Lemma 7 ([28]). Let $X$ be a complete uniformly convex hyperbolic metric space and $K$ be a closed convex subset of $X$ if $\left\{x_{n}\right\}$ is a bounded sequence in $K$, then the asymptotic center of $\left\{x_{n}\right\}$ is in $K$.

We present here a multivalued version of the $M$-iteration process in a hyperbolic metric space, as follows:

$$
\left\{\begin{array}{l}
x_{0} \in C, \\
z_{n}=W\left(x_{n}, u_{n}, x_{n}\right), \quad u_{n} \in T x_{n} \\
y_{n}=v_{n}, \quad v_{n} \in T z_{n} \\
x_{n+1}=w_{n}, \quad w_{n} \in T y_{n} \quad \forall n \in \mathbb{N}
\end{array}\right.
$$




\section{Main Result}

Let us begin the section with the following useful lemma:

Lemma 8. Let $K$ be a nonempty bounded closed convex subset of a complete uniformly convex hyperbolic metric space $X$ with a monotone modulus of uniform convexity and $T: K \rightarrow C(K)$ be a multivalued $\alpha$-Reich-Suzuki nonexpansive mapping. If $\left\{x_{n}\right\}$ is a sequence in $K$, then the following holds:

$$
x_{n} \stackrel{\Delta}{\rightarrow} x, d\left(x_{n}, T x_{n}\right) \rightarrow 0 \text { and } \operatorname{diam}\left(T x_{n}\right) \rightarrow 0 \text { imply } x \in E_{T}
$$

Proof. From Lemma 7, we obtain that $x \in K$. For each $n \in \mathbb{N}$, we can choose $y_{n} \in T\left(x_{n}\right)$ such that $d\left(x_{n}, y_{n}\right)=d\left(x_{n}, T x_{n}\right)$. By passing through a subsequence, we may assume that $\left\{x_{n}\right\}$ is regular relative to $K$. Let $A\left(E,\left\{x_{n}\right\}\right)=x$ and $r=r\left(K,\left\{x_{n}\right\}\right)$. In a similar way to the proof of Lemma 3, we obtain that $x \in E(T)$.

Lemma 9. Let $X$ be a complete 2-uniformly convex hyperbolic metric space and $K$ be nonempty closed convex subset of $X$. Assume that $T: K \rightarrow C(K)$ is a multivalued $\alpha$-Reich-Suzuki nonexpansive mapping with $E_{T} \neq \varnothing$. Let $\left\{x_{n}\right\}$ be the sequence of $M$-iteration defined by (2) with $\alpha_{n} \in[0,1]$. Then, $\lim _{n \rightarrow \infty} d\left(x_{n}, p\right)$ exists for every $p \in E_{T}$.

Proof. Let $p \in E_{T}$, then

$$
\begin{aligned}
d\left(x_{n+1}, p\right) & =d\left(w_{n}, p\right)=H\left(T y_{n}, T p\right) \leq d\left(y_{n}, p\right)=H\left(T z_{n}, T p\right) \\
& \leq d\left(z_{n}, p\right)=d\left(W\left(x_{n}, u_{n}, \alpha_{n}\right), p\right) \\
& \leq \alpha_{n} d\left(x_{n}, p\right)+\left(1-\alpha_{n}\right) d\left(u_{n}, p\right) \\
& =\alpha_{n} d\left(x_{n}, p\right)+\left(1-\alpha_{n}\right) H\left(T x_{n}, T p\right) \\
& \leq \alpha_{n} d\left(x_{n}, p\right)+\left(1-\alpha_{n}\right) d\left(x_{n}, p\right) \\
& =d\left(x_{n}, p\right)
\end{aligned}
$$

for $n \in \mathbb{N}$. Hence, $d\left(x_{n}, p\right)$ is a nonincreasing sequence, which implies $\lim _{n \rightarrow \infty} d\left(x_{n}, p\right)$ exist for every $p \in E_{T}$.

Theorem 1. Let $X$ be a complete 2-uniformly convex hyperbolic metric space and $K$ be a nonempty closed convex subset of $X$. Assume that $T: K \rightarrow C(K)$ is a multivalued $\alpha-$ Reich-Suzuki nonexpansive mapping with $E_{T} \neq \varnothing$. Let $\left\{x_{n}\right\}$ be the sequence of $M$-iteration defined by (2) with $\alpha_{n} \in[0,1]$. Then, $\left\{x_{n}\right\} \Delta$-converges to a endpoint of $T$.

Proof. Fix $q \in E(T)$. Then, by Lemma 4,

$$
\begin{aligned}
d^{2}\left(z_{n}, p\right) & =d^{2}\left(W\left(x_{n}, u_{n}, \alpha_{n}\right), p\right) \\
& \leq\left(1-\alpha_{n}\right) d^{2}\left(x_{n}, p\right)+\alpha_{n} d^{2}\left(u_{n}, p\right)-4 C_{X} \alpha_{n}\left(1-\alpha_{n}\right) d^{2}\left(x_{n}, u_{n}\right) \\
& \leq\left(1-\alpha_{n}\right) d^{2}\left(x_{n}, p\right)+\alpha_{n} H^{2}\left(T x_{n}, T p\right)-4 C_{X} \alpha_{n}\left(1-\alpha_{n}\right) d^{2}\left(x_{n}, u_{n}\right) \\
& \leq\left(1-\alpha_{n}\right) d^{2}\left(x_{n}, p\right)+\alpha_{n} d^{2}\left(x_{n}, p\right)-4 C_{X} \alpha_{n}\left(1-\alpha_{n}\right) d^{2}\left(x_{n}, u_{n}\right) \\
& \leq d^{2}\left(x_{n}, p\right)-4 C_{X} \alpha_{n}\left(1-\alpha_{n}\right) d^{2}\left(x_{n}, u_{n}\right)
\end{aligned}
$$

for $n \in \mathbb{N}$. Thus,

$$
\begin{aligned}
d^{2}\left(y_{n}, p\right) & =H^{2}\left(T z_{n}, T p\right) \leq d^{2}\left(z_{n}, p\right) \\
d^{2}\left(x_{n+1}, p\right) & =d^{2}\left(w_{n}, p\right)=H^{2}\left(T y_{n}, T p\right) \leq d^{2}\left(y_{n}, p\right) \\
& \leq d^{2}\left(z_{n}, p\right) \leq d^{2}\left(x_{n}, p\right)-4 C_{X} \alpha_{n}\left(1-\alpha_{n}\right) d^{2}\left(x_{n}, u_{n}\right) \\
4 C_{X} \alpha_{n}\left(1-\alpha_{n}\right) d^{2}\left(x_{n}, u_{n}\right) & \leq d^{2}\left(x_{n}, p\right)-d^{2}\left(x_{n+1}, p\right) .
\end{aligned}
$$


Since $C_{M}>0$, it follows that

$$
\sum_{n=1}^{\infty} \alpha_{n}\left(1-\alpha_{n}\right) d^{2}\left(x_{n}, u_{n}\right)<\infty .
$$

Thus, $\lim _{n \rightarrow \infty} d^{2}\left(x_{n}, u_{n}\right)=0$, and hence,

$$
\lim _{n \rightarrow \infty} r_{x_{n}}\left(x_{n}, T x_{n}\right)=\lim _{n \rightarrow \infty} d\left(x_{n}, u_{n}\right)=0 .
$$

By Lemma 9, $d\left(x_{n}, p\right)$ converges for all $p \in E_{T}$.

To show $\left\{x_{n}\right\} \Delta$-converges to an endpoint of $T$, it is sufficient to show that $\left\{x_{n}\right\}$ has a unique asymptotic center in $E_{T}$. For this, we suppose that there are subsequence in $\left\{x_{n_{i}}\right\}$ and $\left\{x_{n_{j}}\right\}$ of $\left\{x_{n}\right\}$ with $A\left(x_{n_{i}}\right)=x_{1}$ and $A\left(x_{n_{j}}\right)=x_{2}$.

Since $\operatorname{diam}\left(T x_{n_{i}}\right)=0$, it follows that $x_{1} \in E_{T}$. Similarly, we can get $x_{2} \in E_{T}$. Now, to prove $x_{1}=x_{2}$.

On contrary, suppose that $x_{1} \neq x_{2}$.

$$
\begin{aligned}
\lim _{n \rightarrow \infty} d\left(x_{n}, x_{1}\right) & =\lim _{i \rightarrow \infty} d\left(x_{n_{i}}, x_{1}\right)<\lim _{i \rightarrow \infty} d\left(x_{n_{i}}, x_{2}\right) \\
& =\lim _{n \rightarrow \infty} d\left(x_{n}, x_{2}\right)=\lim _{j \rightarrow \infty} d\left(x_{n_{j}}, x_{2}\right) \\
& <\lim _{j \rightarrow \infty} d\left(x_{n_{j}}, x_{1}\right)=\lim _{n \rightarrow \infty} d\left(x_{n}, x_{1}\right)
\end{aligned}
$$

which is a contradiction. Hence, $x_{n} \stackrel{\Delta}{\rightarrow} x \in E_{T}$.

Theorem 2. Let $X$ be a complete 2-uniformly convex hyperbolic metric space and $K$ be a nonempty closed convex subset of $X$. Assume that $T: K \rightarrow C(K)$ is a multivalued $\alpha$-Reich-Suzuki nonexpansive mapping with $E_{T} \neq \varnothing$. Let $\left\{x_{n}\right\}$ be the sequence of $M$-iteration defined by (2) with $\alpha_{n} \in[0,1]$. If $T$ is semicompact, then $\left\{x_{n}\right\}$ converges strongly to an endpoint of $T$.

Proof. In view of $\sum_{n=1}^{\infty} \alpha_{n}\left(1-\alpha_{n}\right) d^{2}\left(x_{n}, u_{n}\right)<\infty$. By Lemma 6, there exist subsequence, namely $\left\{x_{n_{t}}\right\}$ and $\left\{u_{n_{t}}\right\}$ of $\left\{x_{n}\right\}$ and $\left\{u_{n}\right\}$, respectively such that $\lim _{t \rightarrow \infty} d^{2}\left(x_{n_{t}}, u_{n_{t}}\right)=0$.

Hence, $\lim _{n \rightarrow \infty} r_{x_{t}}\left(x_{n_{t}}, T x_{n_{t}}\right)=\lim _{n \rightarrow \infty} d\left(x_{n_{t}}, u_{n_{t}}\right)=0$.

By the semicompact of the mapping $T$, one can find a stronger convergent sequence $\left\{x_{n_{t}}\right\}$ of $\left\{x_{n}\right\}$ with the strong limit, i.e., $x$. We shall prove that $x \in E_{T}$.

$$
\begin{aligned}
d(x, T x) & \leq d\left(x, x_{n_{t}}\right)+d\left(x_{n_{t}}, T(x)\right) \\
& \leq d\left(x, x_{n_{t}}\right)+\left(\frac{3+\alpha}{1-\alpha}\right) d\left(x_{n_{t}}, T x_{n_{t}}\right)+d\left(x_{n_{t}}, x\right) \\
& \rightarrow 0
\end{aligned}
$$

as $t \rightarrow \infty$. Furthermore,

$$
H\left(T x_{n_{t}}, T x\right) \leq d\left(x_{n_{t}}, z\right) \rightarrow 0 .
$$

Now, we let $v \in T x$ and choose $y_{n_{t}} \in T x_{n_{t}}$ such that $d\left(v, y_{n_{t}}\right)=d\left(v, T x_{n_{t}}\right)$.

Thus,

$$
\begin{aligned}
d(z, v) & \leq d\left(z, x_{n_{t}}\right)+d\left(x_{n_{t}}, y_{n_{t}}\right)+d\left(y_{n_{t}}, v\right) \\
& =d\left(z, x_{n_{t}}\right)+d\left(x_{n_{t}}, y_{n_{t}}\right)+d\left(T x_{n_{t}}, v\right) \\
& \leq d\left(z, x_{n_{t}}\right)+D\left(x_{n_{t}}, T x_{n_{t}}\right)+H\left(T x_{n_{t}}, F x\right) \\
& \rightarrow 0 \text { as } n \rightarrow \infty .
\end{aligned}
$$

Hence, $v=x$ for all $v \in T x$, that is $x=T x$.

Therefore, $x \in E_{T}$.

By Lemma $9, \lim _{n \rightarrow \infty} d\left(x_{n}, x\right)$ exist. Hence $x$ is the strong limit of $\left\{x_{n}\right\}$. 
Theorem 3. Let $X$ be a complete 2-uniformly convex hyperbolic metric space and $K$ be nonempty closed convex subset of $X$. Assume that $T: K \rightarrow C(K)$ be a multivalued $\alpha$-Reich-Suzuki nonexpansive mapping with $E_{T} \neq \varnothing$. Let $\left\{x_{n}\right\}$ be the sequence of M-iteration defined by (2) with $\alpha_{n} \in[0,1]$. If $T$ satisfies condition $(J)$, then $\left\{x_{n}\right\}$ converges strongly to an element of $E_{T}$.

Proof. Using the proof of Theorem 1, we get

$$
\lim _{n \rightarrow \infty} r_{x_{n}}\left(x_{n}, T x_{n}\right)=\lim _{n \rightarrow \infty} d\left(x_{n}, u_{n}\right)=0 .
$$

Since $T$ satisfies condition $(J)$, we have

$$
\lim _{n \rightarrow \infty} d\left(x_{n}, E_{T}\right)=0 .
$$

In the view of Lemma 9, $\left\{x_{n}\right\}$ is Fejer-monotone with respect to $E_{T}$. It now follows from Proposition 1, $\left\{x_{n}\right\}$ converges strongly to an element of $E_{T}$.

\section{Example}

Let $X$ be a set of real numbers and $K=[0,15]$. Define a multivalued mapping $T: K \rightarrow C(K)$ by

$$
T(x)= \begin{cases}0, & \text { if } x \neq 10 \\ {[11,15],} & \text { if } x=10\end{cases}
$$

Clearly, we can see that $T$ is a multivalued $\alpha$-Reich-Suzuki nonexpansive mapping with $E_{T}=\{0\}$.

We finish our paper with the following open problem:

Open Problem: Can we construct a multivalued $\alpha$-Reich-Suzuki nonexpansive in a higher dimension?

\section{Conclusions}

We proved the convergence of the $M$-iteration process to the endpoint of the multivalued $\alpha$-Reich-Suzuki nonexpansive for a hyperbolic metric space. We worked on the hyperbolic metric space as an underlying space, which is a nonlinear space and contained the class of the Banach space property. Thus, our results not only generalized the class of mappings but also extended the class of underlying space. Our Theorem 1 generalized the Theorem 1 of Abdeljawad et al. [29], Theorem 13 of Ulaah et al. [30], and Theorem 3.2 of Ullah et al. [31]. Theorem 2 generalized Theorem 2 of Abdeljawad et al. [29], Theorem 16 of Ullah et al. [30], Theorem 3.5 of Ullah et al. [31], and Theorem 2.2 of Ullah et al. [32]. Our Theorem 3 generalized Theorem 3 of Abdeljawad et al. [29], Theorem 18 of Ulaah et al. [30], Theorem 3.6 of Ullah et al. [31] and Theorem 2.3 of Ullah et al. [32].

Author Contributions: Conceptualization, I.U. and S.A.; Funding acquisition, A.A.N.A.; Methodology, S.A.; Supervision, I.U. and A.A.N.A.; Validation, I.U., S.A. and A.A.N.A.; Writing-original draft, S.A.; Writing-review and editing, I.U. and A.A.N.A. All authors have read and agreed to the published version of the manuscript.

Funding: This research received no external funding.

Institutional Review Board Statement: Not applicable.

Informed Consent Statement: Not applicable.

Data Availability Statement: Not applicable.

Acknowledgments: The authors are very grateful to the anonymous referees for pointing out many typos and valuable comments for the improvement of the paper. Furthermore, we are thankful to one learned referee for suggesting an open problem for our future research. This paper was funded by the university of Jeddah, Saudi Arbia, Under grant No. UJ-20-DR-143. The authors, therefore gratefully acknowledge with thanks the University technical and financial support. 
Conflicts of Interest: The authors declare no conflict of interest.

\section{References}

1. Mann, W.R. Mean value methods in iteration. Proc. Am. Math. Soc. 1953, 4, 506-510. [CrossRef]

2. Ishikawa, S. Fixed points by a new iteration method. Proc. Am. Math. Soc. 1974, 44, 147-150. [CrossRef]

3. Halpern, B. Fixed points of nonexpanding maps. Bull. Am. Math. Soc. 1967, 73, 957-961. [CrossRef]

4. Agarwal, R.P.; Regan, D.O.; Sahu, D.R. Iterative construction of fixed points of nearly asymptotically nonexpansive mappings. J. Nonlinear Convex Anal. 2007, 1, 61-79.

5. Noor, M.A. New approximation schemes for general variational inequalities. J. Math. Anal. Appl. 2000, 251, 217-229. [CrossRef]

6. Ullah, K.; Arshad, M. Numerical reckoning fixed points for Suzuki's generalized nonexpansive mappings via new iteration process. Filomat 2018, 32, 187-196. [CrossRef]

7. Sastry, K.P.R.; Babu, G.V.R. Convergence of Ishikawa iterates for a multivalued mappings with a fixed point. Czechoslov. Math. J. 2005, 55, 817-826. [CrossRef]

8. Panyanak, B. Mann and Ishikawa iteration processes for multivalued mappings in Banach spaces. Comput. Math. Appl. 2007, 54, 872-877. [CrossRef]

9. Rus, I.A. Strict fixed point theory. Fixed Point Theory 2003, 4, 177-183.

10. Aubin, J.P.; Siegel, J. Fixed points and stationary points of dissipative multivalued maps. Proc. Am. Math. Soc. 1980, 78, 391-398. [CrossRef]

11. Chen, L.; Gao, L.; Chen, D. Fixed point theorems of mean nonexpansive set valued mappings in Banach spaces. J. Fixed Point Theory Appl. 2017, 19, 2129-2143. [CrossRef]

12. Espinola, R.; Hosseini, M.; Nourouzi, K. On stationary points of nonexpansive set valued mappings. Fixed Point Theory Appl. 2015, 236, 1-13. [CrossRef]

13. Hosseini, M.; Nourouzi, K.; O'Regan, D. Stationary points of set valued contractive and noexpansive mappings on ultrametric spaces. Fixed Point Theory 2018, 19, 587-594. [CrossRef]

14. Petrusel, A.; Petrusel, G. On Reich's strict fixed point theorem for multi-valued operators in complete metric spaces. J. Nonlinear Var. Anal. 2018, 2 103-112.

15. Panyanak, B. Endpooints of multivalued nonexpansive mappings in geodesic spaces. Fixed Point Theory Appl. $2015,147,1-11$.

16. Reich, S. Fixed points of contractive functions. Boll. dell'Unione Math. Ital. 1972, 5, $26-42$.

17. Saejung, S. Remarks on endpoints of multivalued mappings on geodesic spaces. Fixed Point Thoery Appl. 2016, 52, 1-12. [CrossRef]

18. Panyanak, B. Approximating endpoints of multivalued nonexpansive mappings in Banach spaces. J. Fixed Point Theory Appl. 2018, 20, 1-8 [CrossRef]

19. Chuadchawna, P.; Farajzadeh, A.; Kaewcharoen, A. Convergence theorems and approximating endpoints for multivalued Suzuki mappings in hyperbolic spaces. J. Comput. Anal. Appl. 2020, 28, 903-916.

20. Kudtha, A.; Panyanak, B. Common endpoints for Suzuki mappings in Uniformly convex Hyperbolic spaces. Thai J. Math. 2018, 159-168. Available online: http:/ / thaijmath.in.cmu.ac.th/index.php/thaijmath/article/view/3183 (accessed on 31 May 2021).

21. Pandey, R.; Pant, R.; Rakočevič, V.; Shukla, R. Approximating fixed points of a general class of nonexpansive mappings in Banach spaces with applications. Results Math. 2019, 74, 1-24. [CrossRef]

22. Reich, S.; Shafrir, I. Nonexpansive iterations in hyperblic spaces. Nonlinear Anal. 1990, 15, 537-558. [CrossRef]

23. Kohlenbach, U. Some logical metaheorems with application in functional analysis. Trans. Am. Math. Soc. 2005, 357, 89-128. [CrossRef]

24. Goebel, K.; Reich, S. Uniform Convexity, Hyperbolic Geometry, and Nonexpansive Mappings; Marcel Dekker: New York, NY, USA; Basel, Switzerland, 1984.

25. Goebel, K.; Sekowski, T.; Stachura, A. Uniform convexity of the hyperbolic metric and fixed points of holomorphic mappings in the Hilbert ball. Nonlinear Anal. TMA 1980, 4, 1011-1021. [CrossRef]

26. Goebel, K.; Kirk, W.A. Topics in Metric Fixed Point Theory; Cambridge University Press: Cambridge, UK, 1990.

27. Laokul, T.; Panyanak, B. A generalization of the (CN) inequality and its application. Carpathian J. Math. 2020, 36, 81-90. [CrossRef]

28. Dhompongsa, S.; Kirk, W.; Panyanak, B. Nonexpansive set-valued mappings in metric and Banach spaces. J. Nonlinear Convex Anal. 2007, 8, 35-45.

29. Abdeljawad, T.; Ullah, K.; Ahmad, J.; Mlaiki, N. Iterative Approximation of Endpoints for Multivalued Mappings in Banach Spaces. J. Funct. Spaces 2020. [CrossRef]

30. Ullah, K.; Ahmad, J.; Arshad, M.; de la Sen, M.; Khan, M.S.U. Approximating Stationary Points of Multivalued Generalized Nonexpansive Mappings in Metric Spaces. Adv. Math. Phys. 2020. [CrossRef]

31. Ullaha, K.; Ahmada, J.; Muhammada, N. Approximation of endpoints for multi-valued mappings in metric spaces. J. Linear Topol. Algebra 2020, 9, 129-137.

32. Ullah, K.; Khan, M.S.U.; Muhammad, N.; Ahmad, J. Approximation of endpoints for multivalued nonexpansive mappings in geodesic spaces. Asian-Eur. J. Math. 2020, 13, 2050141. [CrossRef] 